\title{
Religious individualisation in China: a two-modal approach
}

\section{Introduction: individualisation, in society and in religion}

In current sociological and anthropological studies of China, the issue of individualisation is prominent (Hansen, Svarverud 2011). On the one hand, this is a most general concept referring to ideas about modernisation as a project that enhances the rights of the individual and centres on individual aspirations for fulfilling one's goals and values in life. On the other hand, the notion relates to the more specific ideas of Ulrich Beck (2014, 91ff.) about 'reflexive modernisation' which highlights the autonomy and responsibility of the individual regarding the construction of her or his identity as a person (such as even individualising the choice of gender). The difference between the two approaches lies in the respective role of reflexivity. Applied to China, this boils down to distinguishing between two kinds of individualisation. For example, the upsurge of consumerism and self-centred moral attitudes as well as the growth of private entrepreneurship may be regarded as individualisation in the former sense. However, this process of individualisation is triggered by many policies actively promoted by the government, so that it may be conceived as a passive process of adaptation, lacking the criterion of reflexivity. An influential contributor to the debate, Yan Yunxiang (2010), therefore argues that individualisation in China is different from the Western form of individualisation and can be characterised as 'state-led individualisation' or 'authoritarian individualisation'. ${ }^{1}$

1 I cannot go into the details of the discussion, which is more complex, as Beck, for example, distinguishes between 'individualism' and 'individualisation'. However, I think my description catches the gist of the argument. Important empirical studies on 'authoritarian individualisation' have been presented for the educational sector in China, where persons are educated to become 'individuals', see, e.g., Hansen 2013.

Note: Thanks to Bernd-Christian Otto, Martin Fuchs and Philip Clart for extensive comments on an earlier version of this paper. Further, I learned a lot from presenting my ideas at the meetings of the Kollegforschergruppe.

D Open Access. (c) 2019 Carsten Herrmann-Pillath, published by De Gruyter. (ब) BY-NC-ND This work is licensed under a Creative Commons Attribution-NonCommercial-NoDerivatives 4.0 International License. https://doi.org/10.1515/9783110580853-033 
From the angle of this section in our publication on religious individualisation, Yan's argument refers to a peculiar pattern of institutionalisation of individualisation, though evidently in a paradoxical way, as far as established Western notions of that process are concerned: Western observers would mostly tend to see individualisation as a process of establishing autonomy vis à vis authorities external to the individual. Therefore, I want to tackle the issue of individualisation in a different way. Evidently, both conceptions of individualisation in China take for granted that some form of 'collectivist' culture is the starting point from which individualisation proceeds. Indeed, characterising traditional Chinese culture and society as collectivist and group-oriented is a staple across the social sciences, psychology, management sciences, and economics. ${ }^{2}$ I wish to question this assumption and present the hypothesis that China traditionally manifested culturally embedded forms of individualism, which are reflected in certain religious practices. By implication, current tracks of individualisation would not be interpreted as being connected to earlier forms of collectivism, but may stand in line with traditional forms of individualism. ${ }^{3}$ In previous work (Herrmann-Pillath 2016a), I relied on the conceptual and empirical work of one of China's foremost 20th century anthropologists and sociologists, Fei Xiaotong, in debunking claims about the 'collectivism' of Chinese culture, by combining it with recent research in psychology, sociology and cognitive sciences about the values and behavioural stances of the Chinese. In this argument, I already point towards Chinese religion as a potential area to further substantiate this claim.

In the current paper, I will present my case for individualism, 'Chinese style', by connecting the sociological debate to the discourse that is going on in religious studies about religious individualisation (Fuchs 2015), and which lies at the centre of this multi-volume collection of papers on the topic. In this discourse, the conventional idea about individualisation follows the established narrative about Western modernisation: For example, the secular trends following the Reformation, as one revolutionary step in individualisation, manifest phenomena such as increasing protection of religious freedoms of the individual and growing self-determination of religious choices, with a focus on individual religious needs and preferences and inner beliefs and spirituality. However, this master narrative is increasingly questioned, both regarding the historical record and in

2 To mention just one example, extremely influential in economics and management sciences, in the Hofstede approach China appears as diametrically opposed to Western countries in the 'collectivism vs. individualism' dimension, representing a strong case of collectivism (Hofstede et al. 2010).

3 Mirroring this reasoning, one can also argue that individualisation in China today does not exist in tension with the persistence of group-oriented behaviour, especially in traditional forms, see Barbalet 2016. 
cross-cultural comparisons. As for the historical record, the historical ubiquity of deviant forms of religiosity, large local variations in religious expressivity and practice, or the strength of mysticism in Europe may indicate that the notion of individualisation hinges on an uncritical acceptance of hegemonic religious beliefs and organisations as a measure of evaluating these phenomena as marginal. Cross-cultural comparison, in turn, reveals the cultural embeddedness of the analytical notion of individualisation; therefore, we might be blinded to alternative cultural forms of individuality, or even might not be able to appreciate cultural forms that dissolve the analytical dualism between individual and group (such as covered by notions of 'dividuality', Mosko 2010).

I think it is worthwhile to build on this discourse in religious studies and raise the question of religious individualisation in China. ${ }^{4}$ This question has its own interest, but will also contribute to the wider debate over individualisation in Chinese studies more generally. I will argue that the Chinese religious domain manifests many forms of individualism, thus supporting the case for individualisation in Chinese society in the context of both tradition and modernity. In doing this, I introduce a specific analytical framework that is motivated by a recent discussion in Chinese religious studies about the relevance of the 'religious market model' (henceforth, RMM). ${ }^{5}$ In this discussion, David Palmer (2011) criticises applications of the RMM in pointing out that many forms of religious activity in China do not follow the logic of market exchange, but of gift exchange, thus primarily serving as expressions of identities and community. We can refer this to the debate about religious individualisation in general, where we also observe the implicit distinction between individualism in terms of choices and individualism in terms of expressivity. This dualism has been seminally elaborated by Charles Taylor (1989) as an important feature of the European process of individualisation. I suggest that we can therefore think about individualisation in terms of two modes, where market exchange relates with (rational) choice, and gift exchange with expressivity. I submit the claim that an adequate picture of individualisation needs to take both modes into consideration, and analyse their

4 My project is related to Szonyi's (2009) discussion of secularization in comparative terms. Indeed, individualisation is often seen as concomitant to secularization, partly because secularization reduces the grip of religion on society. Interestingly, Szonyi uses the religious market model, which I introduce below, also as an analytical device to analyse secularization in Imperial China, which is methodologically akin to my approach.

5 The RMM was seminally introduced by Iannacone (1991), building on early ideas of Adam Smith. The subsequent literature is aptly reviewed by Höhener and Schaltegger (2012). The journal Religion published a special issue on religious markets in the Chinese context in its issue 41(4) in 2011. One of the most influential authors in this area, Rodney Stark, has also co-authored a study on Taiwan, see Lu et al. 2008. 
systematic interaction. In other words, I think that individualisation is always and everywhere a bimodal phenomenon. This implies that it is dynamic, and that there are recurrent oscillations between the poles which may explain much historical and cross-cultural diversity.

In this context, the RMM has never been considered as a point of reference in the specialised literature about religious individualisation, to the best of my knowledge. I suggest that it can help as an analytical lens to identify specific forms of individualisation that occur during processes of the economisation of society (Çalışkan, Callon 2009; 2010). After all, this is certainly part and parcel of the grand narrative about Western individualisation, and an important aspect in discussing individualisation in China today. Authoritarian individualisation easily can be interpreted as a form of 'neoliberal governmentality', where the market appears as a form of social power, thus actually even reducing the scope for both individual choice and expressivity (Sigley 2006). Yet, the RMM states precisely the opposite in arguing that religious markets enable individual choice, and therefore create a competitive dynamic of providers of religious services fulfilling autonomous individual needs.

Therefore, I think that we can use the RMM as an analytical metaphor in reflecting on the nature and scope of individualisation, without claiming that it also covers the phenomenology of religion in a specific case. In discovering the limits of its applicability, we can also identify the points of transition to the mode of expressivity, following the lines of Palmer's reasoning. Yet, at these points of transition, we could indeed realise even the phenomenological value of the RMM in noticing the emic references to market exchange in religious life, often triggering critical reflection and moves towards the expressive mode.

Another advantage of the RMM is that it implicitly combines the perspectives of institutionalisation and individualisation in its analysis of practices. On the phenomenological level, the empirical vindication of the RMM would rest upon the identification of certain practices, such as competitive behaviour among alternative suppliers of religious services. However, 'markets', even if conceived as a mere metaphor, would include both complex forms of institutionalisation (such as religious rights) and individual behavioural stances (such as entrepreneurial drive). Accordingly, I think that the RMM is particularly powerful in approaching the relationship between institutionalisation and individualisation in the domain of practices.

In the following, I begin with a brief exposition of the RMM. In section 3, I introduce the second mode of expressivity and gift exchange. Section 4 puts the two modes together in a dynamic model of individualisation. Section 5 applies the model to China. Section 6 concludes with an outlook on the implications for the general issue of individualisation in Chinese society. 


\section{Basics of the religious market model (RMM)}

I treat the RMM as a methodological litmus test to explore some deeper aspects of religious individualisation, without claiming that it is sufficient to explain observed phenomena. The RMM is a useful metaphor and heuristic device that highlights certain aspects of individualisation which relate to the economic dimensions of religion, in two senses:

- First, religious activities and religious organisations require economic resources and economic management, which implies that economic motives and concerns always intermingle with religious ones, creating specific motivational and behavioural patterns.

- Second, religious activity is integrated into the larger evolving structures of society, with special relevance of processes of economisation and marketisation, which embed and even drive the individualisation of social agency, resulting in specific forms of economic agency that interact with agency in other domains, as stipulated in the first point. These processes mainly work via certain patterns of institutionalising markets and their embedding social contexts.

The RMM as an empirical hypothesis posits that economic agency is also underlying religious agency, in terms of the rational choice model. I do not make this assumption. The concept of economisation implies that rational choice cannot identify a universal form of agency, but is always contextualised in specific social and cultural forms, partly enshrined in institutions. Economisation means that rational agency is established in social practices, norms, and ideational schemes that themselves evolve, interacting with other forms of agency. It is a process in which the boundaries between 'the economic' and other social domains are continuously negotiated, reproduced and changed.

Originally, the RMM was developed to explain an apparent paradox in the theory of modernisation, as applied to the United States, specifically. This is that secularization and modernisation have not resulted in a decline of religion in terms of religious practices, as indicated by the fact that the United States, although being the most advanced economy in the world, still manifests strong religious activities, such that, for example, in the World Values Survey, the US continues to display 'traditional' values, though also scoring high in so-called 'self-expression values' ${ }^{6}$ The RMM explanation builds on economic theory, espe-

6 See http://www.worldvaluessurvey.org/WVSContents.jsp (last access March 3, 2018). The WVS is designed as a two-dimensional measure of societal modernization, with one dimension defined 
cially rational choice and market theory, in order to solve this apparent paradox. It starts out from recognising a revealed preference for religious services that cater to certain religious needs which are taken as a given, as usual in economics. Based on this, the RMM applies a market model of supply and demand, in which religious organisations are treated as firms. The organisations pursue certain goals, which are not necessarily profit-making, but, for example, pursue expansion of the number of followers ('market share'). The most important analytical ingredient is competition. Competition enforces certain strategies on religious organisations that are responsive to the demand of believers, but also aim at influencing market structure, such as creating monopolies, in the same fashion as business firms design strong brands to which customers are loyal.

The RMM suggests that institutional secularization, together with the legal guarantees of religious freedom, creates' the conditions for an emerging religious market. ${ }^{7}$ In a real-world religious market, it is precisely that freedom of expression and organisational autonomy that leads to the expansion of religion, mediated via enhanced competition, relative to societies where religion remains partly tied to the state. Further, the RMM can even explain certain specific aspects of religion, such as the emergence of especially strict forms of sectarianism in an otherwise secular society, as the outcome of market dynamics and organisational strategies. Clearly, this specific notion of institutionalisation amounts to the standard narrative of growing civic freedoms and individual autonomy in Western modernity.

My interest in the RMM results from the observation that it has been applied with some success in the United States, but seems less appropriate for other cases. ${ }^{8}$ Therefore, I consider the possibility that it is performative. ${ }^{9}$ In a narrow sense, performativity of the RMM would mean that applying the RMM itself would

by the two poles of 'traditional' vs. 'secular-rational' values, and the second by the two poles of 'survival' vs. 'self-expression' values. Over the past twenty years, the US has slowly moved from a comparatively strong position in the traditional values to rational-secular values, yet remains far below Protestant European countries, but, interestingly, also the 'Confucian' countries, including China. The comparative literature on the RMM has not resulted in conclusive empirical evidence even on the secularization thesis, as summarized by Höhener and Schaltegger (2012).

7 This corresponds to Beck's (2014) general argument on individualisation as 'institutionalized individualism'.

8 For an explicit critique of applications to China based on institutional differences, especially the role of the state as a quasi-religious entity, see Liang 2014.

9 In economics, the notion of performativity has been gaining ground, see Boldyrev, Svetlova (2016). The narrow meaning of the term refers to the phenomenon that economic theories do not only describe economic facts, but create them, in the same way as performative utterances in speech act theory. I follow the broader meaning represented by Callon (2007) who does not 
contribute to the emergence of the phenomena that it describes. This is evidently not the case, given the limited reach of the RMM in religious practice (such as, possibly, in guiding management decisions by leaders of religious communities in business-like mega-churches). But in a broader sense, both the RMM and its referents would be conceived as being embedded in certain forms of a market-based society, or, capitalism. Then I would surmise that these forms of life and corresponding forms of thinking give rise both to the specific forms of religiosity and to the RMM as a way of scientifically understanding it. In other words, religion in the US and the RMM would be conjugated cultural forms embedded into a shared larger cultural framework that reflects secular processes of economisation and marketisation which are specific to the US context. This implies that standard forms of applying the RMM are themselves relative to certain cultural frames, and hence cannot be taken as universal patterns of explaining religious phenomena.

However, I think that the RMM as such points towards an important issue in the theory of religious individualisation. This is the interaction between certain forms of individual behaviour and the institutional environment. Taking the market as a theoretical reference implies certain conditions of application that are themselves indicators of individualisation. Most importantly, these are specific individual rights, such as the right of religious self-determination, the right of free expression, or the right of establishing religious organisations. So, the analytical notion of 'market' is highly loaded with assumptions that describe the institutional emergence of individualisation in modern societies. This is recognised by the RMM because it takes secularization for granted, which poses the challenge that RMM intends to meet. One could argue that all these institutional conditions of application are included in the notion of secularization, thus partly resolving the alleged puzzle $a b$ ovo. Then, from the perspective of performativity, we could say that the applicability of the RMM is a sort of litmus test for indicating the existence of its conditions of application. ${ }^{10}$

Regarding our topic of individualisation, we notice that the RMM implies a specific type of individualisation, which is inherent to the general model of a market. This model can be described in terms of concepts such as utilitarian

limit this function to scientific economic theories, but includes all kinds of ideas and concepts relating to the economy.

10 However, one additional condition is to take religious needs for granted. That would mean that secularization as such would not essentially impact the religious needs. This is a view specific to economics, which refrains from explaining preferences at all, starting out from subjectivism as a premise. The strength of religion in the US would be simply seen as manifesting the underlying preferences. Thus, the theory argues that market dynamism reinforces the expression of these needs. 
rationality, autonomy, or analytical separability between individual and society. This form of individualisation has been repeatedly highlighted by many sociologists and philosophers, such as Norbert Elias (1969, xlvi ff.), who coined the term 'homo clausus' in his theory of Western civilisation, or Charles Taylor (1989, 195ff., 305ff.), who distinguishes between two different strands of individualism in European history: the rationalist, which corresponds to the RMM model, and the expressivist. This dualism inspires our next section.

\section{Expressivism and gift exchange}

David Palmer (2011) has thoroughly criticised the application of the RMM to China. Palmer points to different institutional and normative forms of 'religious economy' and opposes market exchange with gift exchange, following classical anthropological theories of gift exchange as stated by Mauss. The central idea is that a gift is not a commodity, because it creates and maintains a social relationship. Whereas in market exchange, payment concludes the social interaction between seller and buyer, exchange of gifts never concludes the social relationship, because the action is perceived as being part and parcel of an ongoing reciprocal exchange. Religious gift exchange is a variant of reciprocal gift exchange because it involves a third party, the transcendental entities. This means that, for example, a giver may not expect reciprocity from the human receiver of the gift, but from the transcendental domain. However, sacrifice may also be interpreted along the lines of dualistic gift exchange, thus establishing a relationship between the Gods and the human giver of the sacrifice. Palmer argues that gift exchange plays an important role also in Chinese religious activities, and can be clearly demarcated from market exchange in empirical terms (for a similar view, see Liang 2014). That means that in the Chinese religious economy the two modes coexist: For example, there are temples that are indeed involved in economic competition over attracting pilgrims and believers, according to the standards of efficacy (ling 靈) in meeting the needs of the visitors, but there are also the communal temples of the villages, which define the relationship between believer and temple in terms of social ascription to the village community as a ritual collective.

I argue that Palmer's critique comes very close to Hénaff's (2002) discussion of the relationship between market exchange and gift exchange, but there is an important clarification to be made. Hénaff criticises the inclusion of gift exchange in the broader notion of economy (which is often done in anthropology), because this opens the door for economic analyses of gift exchange that conflate both 
modes of relationship. Instead, Hénaff emphatically argues that gift exchange is radically different from market exchange in serving the goal of expressing identities in social relationships, in the sense of both individual and shared identities. This radical difference implies that the two modes cannot co-exist in one single pattern of social interaction, because market exchange necessarily undermines the expressive functions of the gift. This is most evident if we consider the role of money in mediating social relationships. Since money is the primordial medium of market exchange, the use of money in reciprocal relations of gift exchanges can undermine their very role in creating and maintaining the underlying shared identities. This is important in the context of this paper, because the relationship between markets and other social domains is strongly influenced by the respective roles of money, with money assuming transformative forces. ${ }^{11}$

Further, I refer Hénaff's reasoning to Taylor's distinction between two forms of individualisation in European cultural history, the rationalist and the expressivist. $^{12}$ If we deal with a particular phenomenon of social relationship, this can be framed in either of the two modes. Here, the methodological dimension comes into play, also in the sense of involving performative phenomena. The two frames are simultaneously phenomenological and analytical. In the analytical sense, we refer to two fundamentally different frames of thinking in intellectual history. The rationalist view is ideal-typically represented in economic theory, which, in a broader sense, also encompasses all approaches that rely on analytical figures such as the social contract. This is exactly the frame that also underlies the RMM, and hence also stipulates a specific form of individualisation, namely the instrumental and rationalist one, in which individuals pursue their goals rationally, and create social institutions based on instrumental rationality, both via exchange and agreement. The expressivist analytical stance is represented by social theories and philosophies that reject the frame of instrumental rationality and instead focus on the role of individual identity and creativity. In this view, individualisation means that the scope and range of individual expressions of

11 This opens perspectives on Simmel's (1907) philosophy of money, which is significant in the current context because Simmel approaches money as a major medium of individualisation, and would imply that a market logic expands across all social domains. However, as Zelizer (1997) has shown in her classical study of money in social relationships, the uses of money are classified differently in social practice, especially distinguishing between money used in market exchange and in gift exchange. I have analysed the performative functions of money extensively in Herrmann-Pillath (2016b).

12 Taylor (1989, 195ff., 305ff.). More specifically, the rationalist tradition is defined in terms of 'atomism' and 'instrumentalism'. Expressivism is also a constant, but was strongly emerging as a counter-current against rationalism, such as in German romanticism; it relates with Republican values in political philosophy, as opposed to rationalist social contract theory. 
identity is enhanced, and necessarily requires the cooperative creation of shared identities based on emotional and symbolic formations.

These two frames also have a phenomenological status. This implies that there is a tension between the analytical and the phenomenological uses, because the two analytical frames are mutually exclusive, but in terms of the phenomenological interpretation they can co-exist, albeit in tension. This is the idea that I wish to explore further in the next section. I argue that the notion of individualisation is two-modal, and that the two modes are manifest in different combinations and dynamics across diverse cultural settings, and across different historical periods. One essential aspect is the relationship between individualisation and economisation: Economisation is deeply shaped by historically specific trajectories of institutional changes, driving the emergence of specific forms of economic agency that interplay with changing forms of religious agency. It is the struggle between those different forms of agency that determines the trajectory that individualisation takes. Therefore, we could argue that institutionalisation of individualisation leaves a space open for multiple trajectories of individualisation in either of the two modes, such that there is no unequivocal relationship between institutionalisation and individualisation, as is often uncritically assumed when reflecting upon the Western experience.

\section{The two-modal approach to religious individualisation}

The two-modal approach to individualisation suggests that, even when referring to the European origin of the distinction, individualisation in the West must be conceived as a multi-faceted phenomenon, manifesting tensions and contradictions. We can use the two modes as an analytical device by which we can identify certain conditions and manifestations of individualisation, while at the same time avoiding claims that one analytical mode is sufficient for explaining observed phenomena, or that entire social and cultural systems are shaped by one form of individualisation. This is because in the phenomenological interpretation, we always need to realise that the two modes co-exist in a dialectical tension. My claim is that in different cultural settings we will find different societal, normative and institutional arrangements that reflect temporary solutions to this dialectical tension, and that one important aspect of individualisation is the individual creativity in discovering these solutions and successfully engaging collectives of actors in adopting these solutions. 
Summarising the discussion in sections 2 and 3, we can arrange the issues in the following way.

\begin{tabular}{lll}
\hline & Market exchange & Gift exchange \\
\hline Rationalism/instrumentalism & Compatibility & Tension \\
\hline Expressivism & Tension & Compatibility \\
\hline
\end{tabular}

Analytically and phenomenologically, rationalism is compatible with market exchange, and expressivism with gift exchange. This also implies a performative relationship: Adopting a rationalist stance is a necessary condition of maintaining market exchange, and vice versa, and gift exchange relies on expressive stances, and vice versa. Analytically it is possible to interpret gift exchange in terms of rationalism, yet phenomenologically the corresponding stances exist in tension, as demonstrated by Hénaff. In other words, instrumentalist gift exchange is counter-performative, at least in the longer run. ${ }^{13}$ This is what directly applies to the RMM, as has been shown by Palmer for the case of China: If participant actors start to perceive the religious domain as a 'market', this triggers a backlash and move towards the gift exchange mode. Yet, this does not mean that the entire social domain of religion does not manifest institutional, normative, and behavioural patterns that can be analysed by the RMM. In a nutshell, applying the RMM analytically means to consider the process of economisation, and this helps to understand general processes of individualisation, and of religious individualisation, specifically.

In some more detail, the notion of individualisation can be related to the market exchange model in an abstract way: Individualisation mode 1 relates with the market exchange mode of relationships. In analytical terms, this mode allows for identifying certain conditions of individualisation, such as certain formal or informal rights of pursuing individual goals. Then, the RMM is a proper analytical tool for understanding religious individualisation, as it allows for recognising behaviours and social practices that relate to established and recognised forms of pursuing individual religious needs, and understanding the corresponding role of instrumental functions in establishing larger organisational phenomena of religion, undergirded by certain institutional arrangements. As an abstract analytical model, the RMM is culturally neutral, but helps in identifying functional equivalences across different cultural contexts, thus also in identifying culturally specific forms of individualisation in the market exchange mode (such as relating the interpretation of evangelical churches in the US as 'firms' to the performance of Daoist temples in Hong Kong).

13 On the notion of counter-performativity, see McKenzie (2007). 
However, in the market exchange mode fundamental issues arise regarding the question how to establish, maintain, and express the identity of the individual as a person who is in continuous social interaction with others. Hence, in the market exchange mode a crisis of identity and authenticity looms. So, individualisation mode 2 emphasises the stability, the commitment and the authenticity of behaviour in expressing and manifesting individual identity as a person; the mode of expression is gift exchange. This unfolds in the fundamental tension between being an individual person and being in need of realising this personhood in a web of social relations. The tension can only be resolved when these relationships are themselves rooted in authenticity and commitment.

Now, I claim that the dialectical relationship between the two modes explains specific patterns of religious individualisation: I do this, first by adopting the different analytical perspectives of the two modes, and second, by understanding the inherent tensions in terms of the phenomenology of religious practices. In other words, in terms of empirically identifiable phenomenon, we observe 'individualisation' as a mix of the two modes, and only analysis can reveal their specific expressions. Religious individualisation is driven by and enabled by the expansion of the religious market, in conjunction with the diffusion of markets in society, or, more generally, processes of economisation. This process builds on the growth of a religious infrastructure, which is itself increasingly diverse and competitive, and goes along with the standardisation of religious practices by different suppliers, such as the formalisation of beliefs and rites of specific communities, which enables expansion of services. The concomitant enhancement of individual freedom of choice enables religious entrepreneurship and creativity.

These developments correspond to the institutionalisation of individualisation and imply the growth of the religious market also in institutional terms, that is, in certain formal or informal rights of religious expression, the diversity of organisational forms offering religious services, and specific ways of regulating the religious market. However, they also create the conditions for a backlash, which I approach as the second mode of individualisation. The second mode emphasizes individuality in terms of personal experience, uniqueness, and authenticity of the religious experience, thus explicitly working against the forces of standardisation, but also against all other forms of external enforcement of religious beliefs and rituals that constrain the religious market. The more the religious market moves to 'commoditisation', the stronger will the incentives become that trigger the transition to individualisation mode 2. This is because, as Hénaff shows in much detail, the economisation of the religious domain raises principled doubts and questions about the very authenticity of the motivations and experiences of religious actors. This tension is literally embodied in the universal conflicts over the role of money in religious activities and organisation. 
The gift exchange mode is more complex. This is because there are two aspects here, related to the fact that social relations and religious relations are superimposed. On the one hand, religious interactions with the transcendental can be approached as a gift exchange relationship by which the believer relates personally with the object of her belief. At the same time, however, this personal relationship is mostly embedded in communities of believers who share this personal experience in creating shared identities, which is also expressed in gift exchange. This makes individualisation 2 complex because personal individualisation can be in tension with the embeddedness in a community, which imposes constraints on individual freedom, understood in terms of individualisation 1.

Thus, we see how the two modes contain the seeds for change, and stay in continuous interaction with each other, as represented in Fig. 1. Individualisation mode 1 often triggers the emergence of alternative religious movements that claim authenticity of the religious experience, thus moving to mode 2 : That is, the role of the 'religious entrepreneur' bridges the two modes, triggering such modal transitions. ${ }^{14}$ There are various more detailed scenarios, in par-

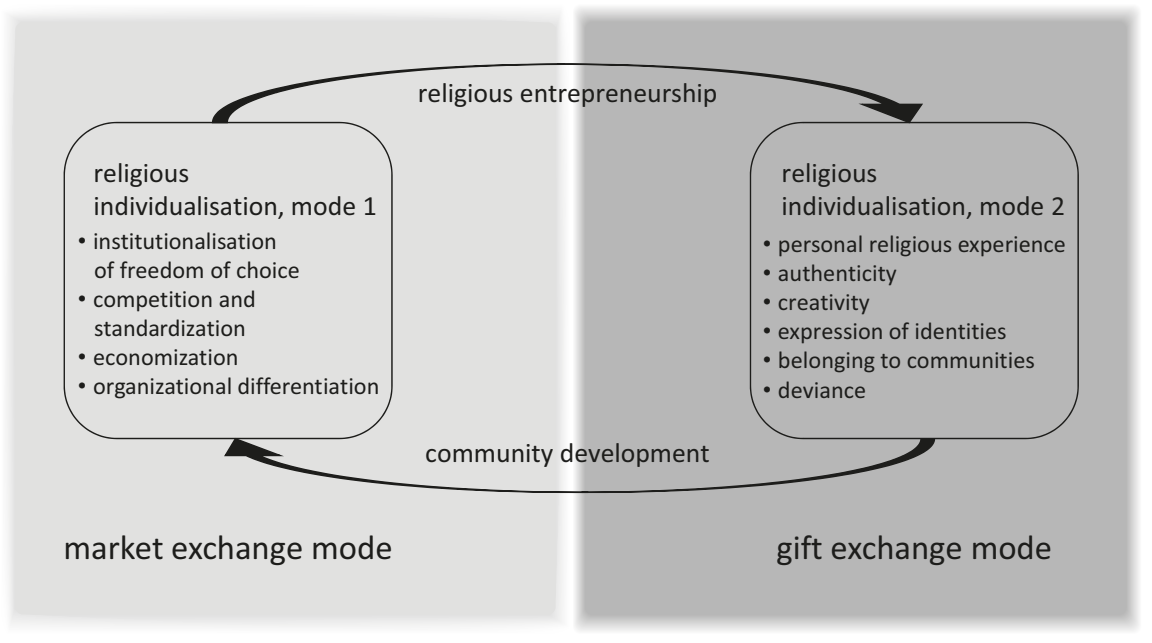

Fig. 1: The two-modal view on religious individualisation.

14 The figure of the religious entrepreneur is ambivalent here, but can be related to a similar duality in Schumpeter's views on market dynamics. There is also the type of entrepreneur (the Wirt) who concentrates on enhancing the efficiency of the organization and expanding its resource base: This type remains within the scope of individualisation 1. But the type of entrepreneur who drives 'creative destruction' is not motivated by economic concerns in the first place: This matches with my notion of religious entrepreneur, and operates in the expressive mode. 
ticular referring to religious markets which are deeply embedded in social and political power structures, thus actually constraining individual freedom of choice via limiting the supply side. In these cases, broader societal developments of marketisation and commoditisation can also drive deviant religious movements, that are originally cast in terms of individualisation 2 , but which eventually also foster individualisation 1 , such as in claiming also rights of religious freedom.

On the other hand, individualisation 2 can foster the expansion of religious communities in the larger context of marketisation. In this case, communities need to build an organizational infrastructure, which requires the mobilisation of economic resources, but also triggers processes of standardisation. So, this mode also harbours forces that go along with individualisation 1 , depending on the broader framework of existing institutional constraints and endogenous forces limiting freedom of choice. This is especially true if communities aim at expansion, which requires raising resources and creates the need for standardising religious practices in the transition to more formal organisation.

In the end, we can envisage cycles of individualisation, for example, with individualisation 1 fostering the emergence of institutionalised freedom of choice, but also engendering switches to mode 2, with religious entrepreneurship operating as a lever connecting the two. Individualisation 2 also goes along with mode shifts to individualisation 1 because of standardisation and economisation in the context of community formation. I posit that these dialectical movements can only be properly understood if we contextualise them in the larger patterns of economisation that take place in different societies. So, the model is both universal and particular: It is analytically universal, but can only be empirically grounded if, phenomenologically, cultural and socio-political embeddedness is explicitly considered.

If I call these movements 'dialectical', this even applies on a deeper level. So far, I have approached the phenomena in the dimension of individualisation, without considering the two poles of this trajectory together. However, one could also argue, for example, that individual dissatisfaction with standardised forms of religious practices in mode 1 in fact responds to their increasing power of de-individualisation, as conceived in mode 2 . This applies vice versa: submission to community ways of life may be felt as encroaching on individual liberties, so being another kind of de-individualisation, but as perceived in mode 1 . Hence, we could argue that the movement between the two modes is driven by their inherent de-individualising forces, as measured in the opposite mode. For reasons of space, I do not pursue this further theoretical development here. 


\section{Religious individualisation, 'Chinese style'}

Applying the model of individualisation to the case of China means that we interpret the empirical evidence about Chinese religious phenomena in the light of the four elements of the model, that is the two poles of market exchange and gift exchange, and the mechanisms that drive the dynamics between the modes. By means of this interpretation, I assess the status, the pattern, and degree of religious individualisation in China.

In doing this, as a starting point it is important to briefly consider the role of the state, because the state is the most important medium by which certain forms of institutionalisation of individualisation emerge and are being reproduced, which are both constraints and enablers of certain practices of individualisation. The modern Communist state continues, but also considerably strengthened the control of religion that was characteristic also for Late Imperial China (Palmer 2010). This observation plays a central role in one of the most prominent applications of the RMM to China, Yang Fenggang's (2006) distinction between the 'red', the 'gray', and the 'black' market of religion. If we look at this phenomenon in the light of the individualisation perspective, however, we can interpret the regulatory role of the state in various ways. The peculiar relationship between state and religion was established in Imperial times to contain religion as a potential source of autonomous power vis à vis the state, often manifested in the role of religion in large-scale uprisings. This motivation clearly is also prevalent today, such as in the case of the suppression of Falungong (法輪功), which did not directly challenge state authority, but revealed organisational capacities that posed a potential threat.

However, this containment of religion has another side of the coin, namely implicitly safeguarding individual freedom of choice in religion, both by limiting the emergence of religious monopolies and by refraining from establishing and enforcing a state religion: This is manifest in the secular growth and richness of the central phenomenon of Chinese religiosity, i.e., popular religion (Clart 2012). The latter assessment might be questioned, however, as the Confucian state cult certainly had a religious dimension (sometimes called a 'civic theology'); beyond that, the Confucian enforcement of certain kinship norms and rituals may also be interpreted as imposing state-backed religious beliefs, as ancestor worship is one of the constitutive elements in popular religion (Ebrey 1985; Faure 2007). Similarly, some observers would argue that Maoism was a substitute state religion, and even contemporary modernist ideologies might have an almost religious status (Goossaert, Palmer 2011, Chap. 7; Liang 2014). Yet, I think that even if we accept the thesis of religious aspects of the Chinese state, this does not imply that a state religion is imposed on society, in the sense of 
a fully-fledged institutionalisation of religious practices. One important limit to this is the rationalism and secularism that shaped both Confucian and contemporary modernisers' thinking about religion, and is visible in the long historical tradition of approaching popular religion as mere 'superstition' (Lagerwey 2010, 2ff.). Battling against superstition in the 20th century, of course, also implies that certain individual rights of religious choice are infringed, but as we know, both Imperial and Communist governments also accommodated popular religion. In the past, this happened via the recognition of spontaneously emerging beliefs in the official pantheon (Watson 2004); in the present, this works via the symbiosis between tourism and ideas about national heritage and popular religion (Clart 2012). This ambivalent attitude of the state has been theoretically and positively described as 'orthopraxy' versus Western 'orthodoxy', meaning that stateled institutionalisation only covered certain sensitive forms of social practice, but firstly, refraining from imposing also certain standardised interpretations of these practices, and secondly, leaving all other practices effectively to the choice of individuals and communities. ${ }^{15}$

Therefore, I conclude that we can diagnose a de facto, though constrained recognition of the freedom of individual choice of religion. ${ }^{16}$ For Yang's RMM model, we can conclude that the very applicability of the market paradigm implies that the entire domain of religion in China manifests properties of a religious market, though under government regulation. By implication, we observe a high degree of individualisation on both the supply and demand side, in terms of the market exchange mode.

This comes to the fore in an approach to Chinese religion that has been developed recently by Adam Chau (2006; 2011). Chau looks at the demand side in more detail, but without referring to the complete RMM. Yet, his point is pertinent. He argues that Chinese religion is 'polytropic', which means that the entire religious domain is shaped by the expressions of different 'modalities of doing religion', such as scriptural, caring for life concerns, or ritualistic. Modalities correspond to different needs that individuals have. Individuals turn to different suppliers in the various modalities, according to need and perceived efficacy. So, polytropy means that the religious domain is not shaped by a hegemonic belief system, but is open, variable, and dynamic. Most importantly,

15 The term 'orthopraxy' was seminally suggested by Watson (1985/2004), Watson and Ebrey (1988) and Schmidt-Glintzer (1983). There is still a lively debate about its merits, see Sutton (2007) and the contributions to this special issue of 'Modern China'.

16 Regarding individual rights in general, Bünger (1983) seminally argued that Western-type notions of rights might not have emerged in China because the state was not as intrusive as in Europe, especially in England after the Norman invasion (on this, see also Foucault 1997). 
it centres on the individual, or, in the Chinese cultural context, the household (which points to the variant of 'family individualism' as highlighted in Chinese studies).

This interpretation is especially relevant when considering the organised religions. Clearly, Buddhism and Daoism easily match with the analytical standards of the RMM because they compete in delivering services to individuals, which also implies a cash nexus. Since the collapse of the Imperial order, these religious groups started to import organisational models of Christianity to strengthen their positions in the Chinese religious domain, introducing hierarchical structures, standardisation, and so forth. At the same time, there is the distinction between lay people and religious experts, with the latter adopting exclusive ties to the respective confessions. However, there is no strict imposition of exclusivity on the laypeople. By contrast, Christianity and Islam always caused tensions in the Chinese religious domain because of their claims to exclusivity. Yet, we can still think of Christianity as competing with other forms of religion in the Chinese religious domain, while even adopting certain assumptions of the RMM in arguing that it is this competition that creates tendencies towards exclusiveness. I shall come back to this important point later, because it refers to the transition to the second mode of individualisation.

I think we even need to diagnose an extremely rich and diverse form of religious individualisation in China, both in the rural and the urban settings. For example, as has been shown by Fisher (2012) for the case study of a large urban Buddhist temple, on the one hand there are the religious experts in Buddhism, and on the other hand, in the foreyard of the temple that is his field site, there is a crowd of individual lay preachers who offer an astonishing diversity of interpretations and opinions related to Buddhism. This is a veritable market microcosm where the different suppliers of religion compete. Remarkably, we do not only observe individualisation on the demand side, but also on the supply side. Further, we also recognise a strong cash nexus, especially relating to the formal organisation, with donations serving as vehicles of obtaining relief of religious needs, without establishing any kind of closer ties of believers to the organisation, which even remains somewhat aloof from the average believer with less financial means.

Fisher's (2008) work also shows how economic dynamics even drive individualisation within the organisation. Quite frequently individual monks aspire to set up their own temples in some other place in China, where they would assume the role of abbot, and thereby also generate income, safeguarding their livelihood now and in old age. This activity clearly is akin to investment, and in fact sometimes does not rely only on donations, but also on investments that require the generation of returns, produced by future donations to the monastery and 
temple. In other words, these activities are almost exemplary instances of religious entrepreneurship in the market exchange mode. ${ }^{17}$

Often, these activities aim at the urbanising rural areas, where religious needs may be strong, and sufficient prosperity is achieved. However, this effort meets with the endogenous dynamics of popular religion in the rural areas. Here, we observe a similar richness and continuity of forms of individualisation. One important difference between the urban and the rural areas certainly is that in the rural areas, the family and, more precisely, the household plays a central role in forms of individualisation. In that context, Adam Chau (2014) noticed another important difference between Western and Chinese forms of religion: In Christianity, the community is the basic unit of religious practice, highlighted in central rites such as communion, whereas in China the household is the central unit. Specifically, in the idea of communion God hosts the believers, whereas in China the household hosts the gods. ${ }^{18}$ This reversal of roles also applies for many Chinese temples if they are built autonomously by local communities: Apart from established religious entities, a temple would additionally host various gods who often represent local histories of religious tradition.

This is not the place to go into details that are well known. What is most important is the fact that therefore in Chinese tradition, often still alive in the rural areas, religion permeates social life, beginning with the fact that the household is at the same time a site of religious activities, beyond the religious role of the family in ancestor worship. ${ }^{19}$ This relates with gender differences, with women playing an essential role in individualising religious activities related to the household, including external activities such as visiting temples (apart from ancestral halls). There is a vast continuum of activities in the field between the

17 In my own fieldwork conducted together with Feng Xingyuan, we met a related example in Ninghai, Zhejiang province, which is a failed investment. A monk arrived there, equipped with funds that were investments, and asked the villagers for complementary donations. The core building of the temple was constructed, with a plaque identifying all donors of the village, but eventually funds were insufficient, and the monk left.

18 Foucault (2004, 177ff., 187) highlights the subordination of the individual to the community in the Christian image of the 'shepherd'. In this sense, formal Christian religion in medieval times was clearly de-individualising. This confirms Bünger's previously mentioned point in the sense that individualisation in the West can be interpreted as a countermovement which was simply not necessary in China, given the high degree of individualisation already present.

19 For a rich elaboration on this, see Yue (2014). This fact had led C. K. Yang (1961) to describe Chinese religion as 'diffuse'. However, this has a somewhat pejorative ring, matching with the modernist Chinese stance since the 1920s to regard only organized religions as 'religion'. In our context, the religious meaning of ordinary life is a major aspect of individualisation. On this peculiar symbiosis of life and religion, see also Gui (2013; 2014). 
household and public forms of religion: For example, religious feasts might be organised on the household level, and sometimes, depending on the charisma of the protagonists, might tie up with larger public activities of temple festivals (Yue 2014).

My point here is that we meet a wide and rich variety of religious entrepreneurship in the rural areas of China, past and present. Again, this is true for both the demand and the supply side: across the fluid boundary of the household and the public domains, these two sides merge, as the household first has a religious need, and then might turn into a supplier fulfilling similar needs of others. Beyond that, the widespread existence of shamans, spirit mediums, or idiosyncratic forms of collective religious activities rooted in local histories, is clear evidence of the individualisation of the supply side of religion (Dean 2003; DuBois 2005). Here, the central notion of 'efficacy' (ling) also points towards to a common yardstick of competitive performance, often extending the impact of suppliers far beyond their local roots, such as local temples attracting visitors from other places.

In this context, we should include the role of local government in both constraining, but also supporting this local religious market today. This is a peculiar aspect of the Chinese governance of religion that needs systematic recognition and seems so far neglected in Chinese religious studies, which mainly focus on the regulatory role of the central government. Especially with regard to analysing the economy, the fundamental dualism between central and local state has paradigmatic analytical status (Pieke 2004; Heberer, Schubert 2008). One intriguing observation about religion in modern China, noticed by many researchers, is the active role of local governments in the 'marketisation' of religion, mostly under the umbrella of tourism (e.g. Oakes 1999; Bruckermann 2016). Although this might sometimes even provide legitimacy for individual religious practices on the part of officials, what counts most in the current discussion is that the appropriation of religion for purposes of tourism strengthens the market exchange mode also in the religious domain proper. This is typically manifest in competing claims on religious sites, beginning with competition over interpretive hegemony, to actual conflict about managerial control (for a case study, see Kang 2009). So, authentic believers might struggle with local government representatives about certain features of the site, or businessmen might try to push original religious activists out of the management committee of a temple site. However, there is also a long tradition in Chinese popular religion where religion stays in a symbiotic relationship with markets, such as in the institution of the temple fair (miaohui 廟會). Today, founding a temple even for economic motives may not simply be a touristic investment, but also, in a deeper sense, an attempt at creating collective social capital and reputation for a community; or even with a genuine religious 
motivation as the first driver, ultimately one may also have the economic prosperity of the community in mind (for a case study, see Chau 2006).

This observation points to the ambivalent role of religious entrepreneurship in China. This is an even more complex and rich field, beyond the forms that we mentioned so far, and relates with what Yang calls the 'gray' market. To a certain extent, this gray market also existed in Imperial China, because it is mainly defined in distinction to the black market. The latter was certainly covered by the notion of 'heretical teachings' (xiejiao 邪教) in Imperial China, which reveals many family resemblances with prohibited religious activity today. In comparison, the 'gray' market covers a broad range of autonomous religious activities which also may not fit into the established forms of tradition. As such, it is also a distinct form of religious modernity in China, including such things as redemptive societies, healing sects, and so forth. Evidently, these need to be counted as manifestations of religious individualisation. Yet, what is most important here is the tension between the two modes that accompanies many religious activities in the gray market. That means, most importantly, that the switch to the gift exchange mode would undermine the logic of market exchange underlying the RMM.

I think this is a crucial step in the analysis: We approached the domain of Chinese religion in terms of the RMM, discovered many forms of individualisation, but now realise that individualisation also means that this religious market generates forces that undermine the very logic of market exchange. We can even say that it is the market itself that creates these countervailing forces, as is even stated by Yang himself (2011): The expansion of the market society, the perceived erosion of morals, and the growing feeling of alienation create the need for religion beyond the use of a service that would just mirror this marketisation process.

This corresponds to Palmer's (2011) argument against the RMM. In a narrower sense, this means that religion would directly oppose the cash nexus, even if monetary flows are involved. This happens, for example, when religious communities are established in the shape of charities, and strictly follow the principle that donations are channelled to the needy, and that this fulfils the religious needs of the lay members of the charity (for a case study, McCarthy 2013). In a broader sense, the tension between market exchange and gift exchange has always been present in the Chinese religious domain. Palmer rightly points out that there were always two types of temples, with one type directly manifesting community identities, and therefore explicitly excluding competition with other providers of religious services. This constellation is one driving force of temple construction in China today, also including ancestor worship where the community is directly defined in ascriptive terms of kinship. There is much religious entrepreneurship involved, but this is only indirectly related with the market exchange logic, mainly 
via the creation of social capital for the entrepreneur. First, religious entrepreneurs contribute to the strengthening of communities via the construction and organisation of religious activities, and only as a derivative effect this also results in social capital and reputation, which might support also their business activities. This argument even applies on the community level: For example, Christian businessmen as members of Christian communities might achieve the reputation of being trustworthy. Yet, it needs emphasis that we are here facing the creative tension between the two modes: This effect can only work if it does not rely on the market exchange logic. ${ }^{20}$

Community formation is the shared feature across an extremely wide range of religious activities in China today, reaching from traditional lineages to villages, over Buddhist lay organisations and Christian house churches, to 'new age' forms of religion, 'Chinese style'. It may be granted that this is also reflected in the RMM, as competition is conceived as strengthening strong ties between believers and religious organisations. Yet, this argument hides the forces that factually create these ties, which cannot themselves follow the market exchange logic. So, I argue that the gift exchange mode is omnipresent in China, and again driven by forces of individualisation. Probably the most impressive recent example of this transition was the rise of Falungong out of what initially appeared to be an entrepreneurial project in the context of Qigong (氣功) movements present in many forms. The rapid transformation into a powerful religious movement was emerging from its increasing role in defining individual identities and their expression in closeknit communities. The spread of Christianity via Protestant 'House churches' also fits into this pattern of expressivist community formation.

The latter proposition follows from the observation that there is no external force that imposes certain ascriptive ties on individuals, apart from kinship. Even regarding the latter, we could again argue that the suppression of traditional kinship by the modern state implicitly implies the protection of individuals against such impositions. Yet, we observe a strong revival of ancestral rites in many places of China, and most interestingly, this is often tied to the local economic strength of kinship groups. This is especially visible in South-East China, where kinship groups (lineages) often could maintain control over land rights, which have become extremely valuable during the recent urbanisation process.

20 A fascinating case study is Cao's (2008; 2009) research on Christian entrepreneurs in Wenzhou, which shows in detail the delicate balance between business leadership and religious leadership, also cast in modernist terms, such as the ‘quality' suzhi 素質 of leaders. Chau's (2006) much cited study of a Black Dragon Temple in Shaanxi highlights the role of a businessman who even retreated from business to become a temple manager, without necessarily internalizing the religious beliefs. 
Based on their economic power, and perceiving the need to counterbalance municipal authorities potentially encroaching their rights, there is a resurgence of kinship-related rituals that express and cement the solidarity of the lineage (Trémon 2015; Herrmann-Pillath, Guo 2017). In this case, we observe the confluence of the two modes in maintaining what is probably a precarious balance, given the forces of social change that eventually will erode the ground on which extended kinship is built in China (such as demographic change).

To round up this section, if we look at the rich and expanding landscape of religious practices in China today, we can employ the two-modal framework as an analytical lens to identify underlying forces of individualisation. There is much scope for religious entrepreneurship, and the reach and scope of religious communities is growing. This can be related to a vibrant religious market that grows out of a distinct pattern of an aggressively secular communist state which gradually retreated from suppressing religion to toleration, thus creating the space for limited religious freedom by default. However, as I will discuss in the conclusion, this observation is different from the thesis of 'authoritarian individualisation', since the revival of religion in China is not driven by the state.

\section{Conclusion}

We can resolve the conflicting perspectives on the RMM and gift exchange in Chinese religion through arguing that both analytical perspectives grasp the two modes of what I conceive as an integral process of individualisation. The dynamics of this process are driven by the dialectics of these two modes, contextualised in the specific societal, political, and cultural setting. Based on this, I claim that the Chinese religious domain manifests many and strong phenomena of religious individualisation. I also think that we can extend this diagnosis into Imperial times, which, however, would be the topic of another study. ${ }^{21}$

This result is of high significance for the general debate about individualisation in China. Yan Yunxiang believes that this differs from the Western pattern because it is driven by the state. The case of religious individualisation does not confirm this claim. Here, the state contains the religious creativity of people, across all social domains, from rural to urban, so that we cannot say that the state

21 As stated in the beginning, this matches with Szonyi's (2008) analysis of secularization, which covers different historical periods. The paradigmatic debates in historical religious studies on China, such as the issue of 'orthopraxy', can be easily tied up with individualisation in historical times. 
pushes people into individualisation, but to the contrary, tries to keep it within boundaries defined by the state. On the other hand, we also cannot say that the state fosters individualisation beyond religion just because the government suppresses religion and, hence, allegedly 'collectivist' forms of social organisation in China. This follows from our re-evaluation of Chinese religious practices in the light of the two-modal framework of religious individualisation. In Chinese popular religion, the household and the individual play a central role in shaping religious activity. There is a rich dynamic of creating all forms of modern religiosity, unless contained by the state. Paradoxically, the other side of containment by the state is that there are large spaces of freedom, which are filled by individual religious initiative. I have argued that this can be partly covered by the RMM, which we can therefore use as an analytical litmus tests for identifying religious individualisation in China. Hence, we diagnose a distinct pattern of institutionalisation, individualisation and practices that is far more complex than the thesis of 'authoritarian individualisation' suggests.

Therefore, in the religious domain we can find support for autonomous forms of individualisation in China: In other words, religious individualisation is an important aspect of the individualisation of Chinese society in general. That may come as a surprise to many Western observers who, following the Western narrative of modernisation, would tend to see religion as a social force that works against individualisation. Yet, we can argue, as has been done for the case of Taiwan (Weller 2004), that in the specific political and economic context of China, religion becomes an important foundation for individualisation and hence a defining feature of modernity.

\section{References}

Barbalet, Jack. 2016. 'Chinese Individualization, Revisited', Journal of Sociology 52, no. 1. 9-23. Beck, Ulrich. 2014. Ulrich Beck. Vol. 18. SpringerBriefs on Pioneers in Science and Practice. Cham: Springer International Publishing. http://link.springer.com/10.1007/978-3-31904990-8 (last access March 3, 2018).

Boldyrev, Ivan und Ekaterina Svetlova. 2016. 'After the Turn: How the Performativity of Economics Matters', in Boldyrev, Ivan and Ekaterina Svetlova (eds.), Enacting Dismal Science: New Perspectives on the Performativity of Economics. Perspectives from Social Economics. New York: Palgrave MacMillan, 1-28.

Bruckermann, Charlotte. 2016. 'Trading on Tradition: Tourism, Ritual, and Capitalism in a Chinese Village', Modern China 42(2). 188-224.

Bünger, Karl 1983. 'Das chinesische Rechtssystem und das Prinzip der Rechtsstaatlichkeit.' In Max Webers Studie über Konfuzianismus und Daoismus: Interpretation und Kritik, ed. W. Schluchter, Frankfurt a.M.: Suhrkamp. 134-73. 
Çalışkan, Koray and Callon, Michel. 2009. 'Economization, part 1: Shifting Attention from the Economy Towards Processes of Economization', Economy and Society, 38(3). 369-398.

Çalışkan, Koray and Callon, Michel. (2010) 'Economization, part 2: A Research Programme for the Study of Markets', Economy and Society, 39(1). 1-32.

Callon, Michel 2007. 'What Does It Mean to Say That Economics is Performative?' in MacKenzie, D., F. Muniesa and L. Siu (eds.), Do Economists Make Markets? On the Performativity of Economics, Princeton und Oxford: Princeton University Press, 344-357

Cao, Nan Lai. 2008. 'Boss Christians: The Business of Religion in the Wenzhou Model of Christian Revival', The China Journal 59. 63-88.

Cao, Nan Lai. 2009. 'Raising the Quality of Belief: Suzhi and the Production of an Elite Protestantism', China Perspectives 2009/4. 54-65.

Chau, Adam Y. 2006. Miraculous Response: Doing Popular Religion in Contemporary China. Stanford: Stanford University Press.

Chau, Adam Y. 2011. 'Modalities of Doing Religion and Ritual Polytropy: Evaluating the Religious Market Model from the Perspective of Chinese Religious History', Religion 14(4). 547-68.

Chau, Adam Y. 2014. 'Household Sovereignty and Religious Subjectification: China and the Christian West Compared', Studies in Church History 50. 494-506.

Clart, Philip. 2012. 'Chinese Popular Religion.' In The Wiley-Blackwell Companion to Chinese Religions, ed. R. Nadeau, Oxford: Wiley-Blackwell. 219-35.

Dean, Kenneth. 2003. 'Local Communal Religion in Contemporary South-east China', The China Quarterly 174. 338-58.

DuBois, Thomas D. 2005. The Sacred Village: Social Change and Religious Life in Rural North China. Honolulu: University of Hawai'i Press.

Ebrey, Patricia B. 1985. 'The Chinese Family and the Spread of Confucian Values.' In The East Asian Region: Confucian Heritage and Its Modern Adaptation, ed. G. Rozman, Princeton: Princeton University Press. 45-83.

Elias, Norbert. 1969. Die höfische Gesellschaft. Untersuchungen zur Soziologie des Königtums und der höfischen Aristokratie, Frankfurt am Main: Suhrkamp.

Faure, David. 2007. Emperor and Ancestor: State and Lineage in South China. Stanford: Stanford University Press.

Fisher, Gareth. 2008. 'The Spiritual Land Rush: Merit and Morality in New Chinese Buddhist Temple Construction', The Journal of Asian Studies 67, no. 1. 143-70.

Fisher, Gareth. 2012. 'Religion as Repertoire: Resourcing the Past in a Beijing Buddhist Temple', Modern China 38, no. 3. 346-76.

Foucault, Michel. 2004. Sécurité, territoire, population. Cours au Collège de France, 1977-1978. Paris: Seuil.

Fuchs, Martin. 2015. 'Processes of Religious Individualisation: Stocktaking and Issues for the Future', Religion 45, no. 3. 330-43.

Goossaert, Vincent; Palmer, David A. 2011. The Religious Question in Modern China. Chicago: Chicago University Press.

Gui Hua 桂华. 2014. Li yu shengming jiazhi. Jiating shenghuo Zhong de daode, zongjiao yu fal, 礼与生命价值。家庭生活中的道德, 宗教与法律, Beijing: Commercial Press.

Gui Hua 桂. 2013. 'guo rize' yu yuanman rensheng - nongcun zongjiao shenghuo jiben xingtai 过日子于圆满人生一农村宗教生活的基本形态. Ershiyi shiji二十一世纪 140. 40-54.

Hansen, Mette H. 2013. 'Learning Individualism: Hesse, Confucius, and Pep-Rallies in a Chinese Rural High School', The China Quarterly 213.60-77. 
Hansen, Mette H.; Svarverud, R. (eds.). 2011. iChina: The Rise of the Individual in Modern Chinese Society. Copenhagen: NIAS Press.

Heberer, Thomas; Schubert, Gunter. 2012. 'County and Township Cadres as a Strategic Group: A New Approach to Political Agency in China's Local State', Journal of Chinese Political Science 17. 221-49.

Hénaff, Marcel. 2002. Le prix de la verité: le don, l'argent, la philosophie. Paris: Seuil.

Herrmann-Pillath, Carsten. 2016a. 'Fei Xiaotong's Comparative Theory of Chinese Culture: Its Relevance for Contemporary Cross-disciplinary Research on Chinese "Collectivism”, Copenhagen Journal of Asian Studies 34(1). 25-57.

Herrmann-Pillath, Carsten. 2016b. 'Constitutive Explanations in Neuroeconomics: Principles and a Case Study on Money', Journal of Economic Methodology 23(4). 374-95.

Herrmann-Pillath, Carsten; Guo, Man. 2017. 'Ritual and property: Theorizing a Chinese case', Man and the Economy, DOI 10.1515/me-2017-0004.

Hofstede, Geert; Hofstede, G. J.; Minkov, M. 2010. Cultures and Organizations: Software of the Mind. New York: McGraw Hill.

Höhener, Janine; Schaltegger, Christoph A. 2012. 'Religionsökonomie: Eine Übersicht', Perspektiven der Wirtschaftspolitik 13(4). 387-406.

Iannaccone, L. R. 1991. 'The Consequences of Religious Market Structure: Adam Smith and the Economics of Religion', Rationality and Society 3, no. 2. 156-77.

Kang, Xiao. 2009. 'Two Temples, Three Religions, and a Tourist Attraction: Contesting Sacred Space on China's Ethnic Frontier', Modern China 35(3). 227-55.

Lagerwey, John. 2010. China. A Religious State. Hong Kong: Chinese University Press.

Liang, Yongjia. 2014. 'Morality, Gift and Market: Communal Temple Restoration in Southwest China', The Asia Pacific Journal of Anthropology 15, no. 5. 414-32.

Lu, Y.; Johnson, B.; Stark, R. 2008. 'Deregulation and Religious Market in Taiwan: A Research Note', Sociological Quarterly 49.139-53.

MacKenzie, Donald. 2007. 'Is Economics Performative? Option Theory and the Construction of Derivatives Markets.' In Do Economists Make Markets? On the Performativity of Economics, eds. D. MacKenzie, F. Muniesa, L. Siu, Princeton/Oxford: Princeton University Press. 54-86.

McCarthy, S. K. 2013. 'Serving Society, Repurposing the State: Religious Charity and Resistance in China', The China Journal 70. 48-72.

Mosko, Mark. 2010. 'Partible Penitents: Dividual Personhood and Christian Practice in Melanesia and the West', Journal of the Royal Anthropological Institute (N.S.) 16. 215-40.

Oakes, Tim. 1999. 'Eating the Food of the Ancestors: Place, Tradition, and Tourism in a Chinese Frontier River Town', Ecumene 6:2.123-45.

Palmer, David. 2011. 'Gift and Market in the Chinese Religious Economy', Religion 41(4). 569-94.

Pieke, Frank N. 2004. 'Contours of an Anthropology of the Chinese State: Political Structure, Agency and Economic Development in Rural China', Journal of the Royal Anthropological Institute 10(3). 517-38.

Schmidt-Glintzer, Helwig. 1983. 'Viele Pfade oder ein Weg? Betrachtungen zur Durchsetzung der konfuzianischen Orthopraxie.' In Max Webers Studie über Konfuzianismus und Daoismus: Interpretation und Kritik, ed. W. Schluchter, Frankfurt a.M.: Suhrkamp. 298-341.

Sigley, Gerald. 2006. 'Chinese Governmentalities: Government, Governance and the Socialist Market Economy', Economy and Society 35(4). 487-508. 
Simmel, Georg. 1907. Philosophie des Geldes, second edition, reprint 2009, Cologne: Anaconda.

Sutton, D. S. 2007. 'Ritual, Cultural Standardization, and Orthopraxy in China: Reconsidering James L. Watson's Ideas', Modern China 33(1). 3-21.

Szonyi, Michael. 2009. 'Secularization Theories and the Study of Chinese Religions', Social Compass 56, no. 3. 312-27.

Taylor, Charles M. 1989. Sources of the Self: The Making of Modern Identity. Cambridge: Harvard University Press.

Trémon, Anne-Christine. 2015. 'Local Capitalism and Neoliberalization in a Shenzhen Former Lineage Village', Focaal 71. 71-85.

Watson, James L.; Watson, Rubie S. 2004. Village Life in Hong Kong: Politics, Gender, and Ritual in the New Territories. Hong Kong: Chinese University Press.

Watson, James L.; Rawski, Evelyn (eds.). 1988. Death Ritual in Late Imperial and Modern China. Berkeley: University of California Press.

Weller, R. P. 2004. 'Worship, Teachings, and State Power in China and Taiwan.' In Realms of Freedom in Modern China, ed. W. C. Kirby, Stanford: Stanford University Press. 285-316.

Yan, Yunxiang. 2010. 'The Chinese Path to Individualization', British Journal of Sociology 61(3). 489-512.

Yang, Fenggang. 2006. 'The Red, Black and Grey Markets for Religion in China', Sociological Quarterly 47. 93-122.

Yang, Fenggang. 2011. 'Market Economy and the Revival of Religions.' In Chinese Religious Life, eds. D. Palmer, G. Shive, P. L. Wickeri, Oxford: Oxford University Press. 209-26.

Yang, C. K. 1961. Religion in Chinese Society: A Study of Contemporary Social Functions of Religion and Some of Their Historical Factors. Berkeley: University of California Press.

Yue, Yongyi. 2014. 'Holding Temple Festivals at Home of Doing-gooders: Temple Festivals and Rural Religion in Contemporary China', Cambridge Journal of China Studies 9(1). 48-95.

Zelizer, Viviana A. 1997. The Social Meaning of Money. Princeton: Princeton University Press. 